\title{
EL DERECHO INTERNACIONAL PENAL Y LA JURISDICCIÓN UNIVERSAL EN EL CASO SLOBODAN MILOSEVIC
}

\section{Juan Carlos VELÁZQUEZ ELIZARRARÁS*}

RESUMEN: El autor invita a reflexionar sobre la importancia que reviste para la justicia internacional penal contemporánea, el proceso que se sigue a Slobodan Milosevic, ante el Tribunal Penal Internacional ad hoc para la ex-Yugoslavia, entre otras razones por su presunta responsabilidad penal individual en la comisión de crímenes de guerra y crímenes de lesa humanidad. El caso Milosevic es altamente relevante no sólo por la lucha de la sociedad internacional contra la impunidad, sino porque se vincula y relaciona con un grupo más grande de inculpados: líderes políticos, militares, paramilitares y hasta grupos de voluntarios civiles.

ABSTRACT: The author invites us to consider the importance for contemporary international criminal justice, of the process against Slobodan Milosevic before the International Criminal Tribunal for the Former Yugoslavia; for his alleged individual responsibility for committing war crimes and crimes against humanity, among other reasons. The Milosevic case is highly relevant due not only to the struggle of the international community against impunity, but also because it is related to a larger group of suspects: political, military, and paramilitary leaders, or even groups of volunteering civilians.

RÉSUMÉ: L'auteur invite à réfléchir sur l'importance qu'a, pour la justice pénale internationale, le procès de Slobodan Milosevic devant le Tribunal Pénal International ad hoc pour l'ex-Yougoslavie, entre autres raisons pour sa présomption de responsabilité pénale individuelle dans la commission de crimes de guerre et de crimes contre l'humanité. Le cas Milosevic est exemplaire de la lutte de la société internationale contre l'impunité, et de plus ce cas est relié à un groupe plus grand d'inculpés: leaders politiques, militaires, paramilitaires et même des groupes volontaires civils.

* Profesor de la Facultad de Ciencias Políticas y Sociales, y de la Facultad de Derecho de la UNAM; el autor desea agradecer in extenso la camaradería académica del licenciado Raymundo García García, titulado recientemente con mención honorífica en la Especialidad en Relaciones Internacionales (FCPS), con quien comparte una profunda inclinación por el estudio del derecho internacional penal, y sin cuya invaluable colaboración intelectual no hubiera sido posible la presente contribución. 
Aunque los detalles del razonamiento varían, la proposición básica común a todos... es que la tortura constituye un delito internacional sobre el que el derecho internacional y las Partes en la Convención sobre la Tortura han concedido jurisdicción universal a todos los tribunales independientemente del lugar donde se practique la tortura.

Caso Regina $v$. Bartle ex parte Pinochet, Cámara de los Lores, marzo 24, 1999.

SUMARIO: I. El protagonismo de Slobodan Milosevic a partir de la desintegración de Yugoslavia. II. Se refuerza la intervención de la ONU y la acción directa de la OTAN. III. La Constitución del Tribunal Penal Internacional para la antigua Yugoslavia. IV. El proceso seguido a Slobodan Milosevic ante el Tribunal Penal Internacional para la antigua Yugoslavia. V. Desarrollo general de las comparecencias en el juicio a Slobodan Milosevic. VI. Comentarios finales.

\section{EL PROTAGONISMO DE SLOBODAN MILOSEVIC A PARTIR DE LA DESINTEGRACIÓN DE YUGOSLAVIA}

Al interior de la Federación se alzaba la figura de Slobodan Milosevic, un político serbio que accedió al poder en 1987 mediante un discurso nacionalista que exacerbaba los sentimientos de los serbios y proclamaba la conformación de una "gran Serbia". Su proyecto político consistía en un gobierno monolítico y autoritario, un fuerte discurso nacionalista, así como la eliminación de grupos opositores al régimen. A partir de 1989, el gobierno de Milosevic comenzó a sufrir los primeros estragos de sus políticas dictatoriales, con el resquebrajamiento de la Federación de Yugoslavia. Este proceso de guerras independentistas provocó serios enfrentamientos internos o locales, que por la crueldad de las acciones bélicas llevadas a cabo llamaron la atención de la comunidad internacional que hubo de intervenir en las hostilidades en su aspecto humanitario y que incluso, por sus mismas características, invocaron el principio de jurisdicción internacional a través de la instauración de una instancia supranacional encargada de fincar responsabilidad penal por las atrocidades cometidas contra la población civil, y que ahora, a través del Tribunal Penal Internacional para la antigua Yugoslavia, se encuentra sentenciado, entre otras razones, por su demostrada responsabilidad penal individual, lo mismo que una se- 
rie de individuos-órganos e individuos-personas privadas, acusados de cometer crímenes de guerra y crímenes de lesa humanidad; de entre quienes se destaca, por su calidad de individuo-jefe de Estado, Slobodan Milosevic.

\section{SE REFUERZA LA INTERVENCIÓN DE LA ONU Y LA ACCIÓN DIRECTA DE LA OTAN}

Con la situación que se vivía en Bosnia-Herzegovina, el Ejército Popular Yugoslavo, controlado por los serbios, pondría en sitio a la ciudad de Sarajevo (capital de Bosnia), lo que originó la imposición de sanciones por parte de la ONU, las cuales, como manifestación de la fuerza político-militar de la Organización del Tratado del Atlántico Norte (OTAN) le darían el poder de ser la encargada de llevar a cabo tales medidas, no sin antes darse el aumento del número de fuerzas de pacificación de las Naciones Unidas, principalmente británicas y francesas, además de que en mayo de 1992, la ONU estableció mayores sanciones económicas y comerciales contra Serbia y Montenegro, a las que como respuesta siguió una ofensiva contra Gorazde (ciudad al Este de Sarajevo), que era controlada por musulmanes. ${ }^{1}$

Tras múltiples conversaciones y contactos promovidos por la comunidad internacional, el 21 de noviembre de 1995, en la base aérea estadounidense de Wright-Patterson, situada en la ciudad de DaytonOhio, se firmaron los Acuerdos de Dayton, promovidos por Estados Unidos de América, que se proponía poner fin al conflicto. En Dayton, los dirigentes de los Estados en conflicto signaron los documentos de paz: el presidente serbio Slobodan Milosevic, el presidente bosnio Alija Izetbegovic y el presidente croata Franjo Tudjman. De estos acuerdos, se conformó un

1 En julio de 1992 en Londres, líderes serbios, croatas y musulmanes firmarían el primer acuerdo de alto al fuego, al que seguirían otros más, los cuales no fueron respetados. En este año, la situación sería especialmente caótica, pues el conflicto daba plenas señales de nulo respeto al derecho internacional general y al derecho internacional humanitario, ya que comenzó a aplicarse una política de limpieza étnica, incluso declarada abiertamente por grupos serbios en contra de poblaciones sobre todo de origen musulmán, incurriendo en crímenes de lesa humanidad como la persecución, exterminio, asesinato, privación ilícita de la libertad, tortura, deportación, traslados forzosos, genocidio y apropiación ilícita de bienes, entre otros, lo que daba señales claras de ser una guerra de verdadera eliminación étnica. En octubre de 1992, en una reunión convocada por la ONU, a la que asistieron representantes serbios, croatas y musulmanes, tampoco se llegaría a algún acuerdo efectivo de paz; por el contrario, Serbia conquistaría más territorios de las fuerzas croatas y musulmanas, éstas últimas poseían un armamento más ligero: en Sarajevo continuaría el sitio y los esfuerzos de Naciones Unidas resultarían vanos. 
"grupo de contacto" por Estados Unidos de América, el Reino Unido, Francia, Alemania, Italia y Rusia, quienes estarían a cargo del mantenimiento de la paz en los territorios de la antigua Yugoslavia.

Sin embargo, los resultados no fueron fructíferos y sí en cambio se recrudecieron las hostilidades, lo cual llevó a la OTAN, a mediados de 1998, a realizar maniobras aéreas cerca de la frontera serbia al sur de Kosovo, y en territorios de Albania y Macedonia, como formas de presión a Milosevic para que éste detuviera la represión contra la población albanesa de Kosovo. El resultado fue que al día siguiente, Milosevic se comprometió, ante el presidente ruso Boris Yeltsin, a aceptar las condiciones para la paz impuestas por la comunidad internacional. ${ }^{2}$ En octubre de 1998, de nuevo la UE, los EUA y la propia OTAN exigieron a Milosevic que obedeciera el mandato de la ONU de proceder al alto el fuego, esta vez se exigía que fuera de forma irreversible y verificable, ante lo cual el presidente yugoslavo accedió a través de la mediación estadounidense, llegando a un acuerdo que detuvo las amenazas de ataque aéreo que había dispuesto la OTAN, aceptándose la presencia en Kosovo de dos mil supervisores de la Organización para la Seguridad y la Cooperación Europeas (OSCE). A finales de dicho mes, la OTAN desistió de intervenir en la región, ya que argumentaba que se había verificado el cumplimiento de lo acordado, aun cuando continuó manteniendo disuasión militar sobre Serbia.

2 Las principales resoluciones del Consejo de Seguridad en la crisis de los Balcanes son las siguientes: RES/713, septiembre 25, 1991: Cese al fuego, solución pacífica y embargo de armas a los beligerantes; RES/721, noviembre 27, 1991: Establecimiento de una fuerza internacional de paz en la zona conflictual; RES/777, septiembre 19, 1992: Negativa a la solicitud de la RFY a ingresar como miembro de ONU; RES/808, febrero 22, 1992: Creación de un Tribunal Penal Internacional ad hoc para la ex-Yugoslavia; RES/827, mayo 25, 1993: La ratione temporis del TPIY será de enero 1/1991 al retorno de la paz regional; RES/847, junio 30, 1993: Despliegue de Fuerza de Protección de NU sobre Croacia para ayuda humanitaria; RES/870, octubre 1o. de 1993: Ampliación de esta Fuerza de NU hacia territorios en disputa Bosnia-Serbia; RES/943, 1994: Cierre de fronteras entre Bosnia y Serbia, permitiendo sólo paso de medicinas y alimentos; RES/1003, junio 5, 1995: Suspensión del cierre de fronteras entre Bosnia y Serbia; RES/1034, diciembre 21, 1995: Condena de violaciones al derecho internacional humanitario y solución pacífica; RES/1160, marzo 31, 1998: Embargo de venta de armas a la RFY y a Kosovo, condena de la violencia de Serbia contra kosovares y al terrorismo del Ejército de Liberación de Kosovo; insta a la solución pacífica; RES/1199, septiembre 23, 1998: Condena excesiva violencia serbia contra albano-kosovares; preocupación de ONU por numerosos refugiados kosovares; solicita a Serbia acceso de misión de observadores de la UE; RES/1203, octubre 24, 1998: Celebra acuerdos firmados entre la RFY y la OSCE, así como con la OTAN; RES/1239, mayo 14, 1999: Encomienda a ACNUR y a otros Estados brindar apoyo humanitario a los refugiados en Kosovo; pide a la RFY permita acceso al personal de la ONU para llevar ayuda humanitaria; RES/1244, junio 10, 1999: Se exige al gobierno serbio detención inmediata de la violencia en Kosovo, y facilidades para retorno de refugiados y acceso para vigilancia de dicho retorno de kosovares. 


\section{LA CONSTITUCIÓN DEL TRIBUNAL PENAL INTERNACIONAL PARA LA ANTIGUA YUGOSLAVIA}

El Tribunal Penal Internacional para la antigua Yugoslavia (TPIY, o ICTY por sus siglas en inglés) fue instituido con base en su Estatuto elaborado por el Consejo de Seguridad de las Naciones Unidas conforme a las resoluciones 808 (22 de febrero de 1993) y 827 (25 de mayo de 1993), actuando en virtud del capítulo VII de la Carta de la Organización. ${ }^{3}$ El tribunal fue formalmente establecido el 17 de noviembre de 1993 para juzgar a los presuntos responsables de graves violaciones al derecho internacional humanitario, cometidas en el territorio de la antigua Yugoslavia a partir de 1991, y que tiene su sede en La Haya, ciudad-sede del gobierno del Reino de los Países Bajos. Conforme al artículo 2o. del Estatuto del TPIY, el tribunal tiene el poder de juzgar y sancionar, con base en los Convenios de Ginebra, actos tales como: matar intencionalmente, tortura, tratos inhumanos, incluyendo experimentos biológicos; infligir deliberadamente graves sufrimientos o atentar contra la integridad física o la salud; destrucción masiva y apropiación de bienes no justificadas por necesidad militar, y llevadas a cabo ilícita y arbitrariamente; obligar a los prisioneros de guerra o a civiles a servir en las fuerzas de una potencia enemiga; privar deliberadamente a un prisionero de guerra o a un civil del derecho a un juicio justo y regular; deportación ilegal o traslado y enciero ilícito de civiles, así como la toma de civiles como rehenes.

El TPIY tiene competencia para juzgar a las personas que cometan o hayan dado la orden de cometer infracciones graves contenidas en las Convenciones de Ginebra de 12 de agosto de 1949, dirigidas contra personas o bienes protegidos por los términos de las disposiciones de dichas convenciones: ${ }^{4}$

3 El capítulo VII de la Carta de las Naciones Unidas, es el relativo a la acción en caso de amenaza a la paz, quebrantamiento de ésta o actos de agresión, el cual, en el artículo 39 de dicho capítulo, establece que el Consejo de Seguridad determinará la existencia de toda amenaza a la paz, quebrantamiento de la paz o acto de agresión y hará recomendaciones o decidirá qué medidas serán tomadas - medidas que no impliquen el uso de la fuerza armada o, si éstas demostraran ser inadecuadas, ejercer acciones por medio de fuerzas aéreas, navales o terrestres-, para mantener o restablecer la paz y la seguridad internacionales.

4 Los cuatro convenios de Ginebra de 12 de agosto de 1949 (desde 1950 en vigor) y sus protocolos comprenden: Convenio I de Ginebra del 12 de agosto de 1949 para Aliviar la Suerte que Corren los Heridos y los Enfermos de las Fuerzas Armadas en Campaña; Convenio II de Ginebra para Aliviar la Suerte que Corren los Heridos, los Enfermos y los Náufragos de las Fuerzas Armadas en el Mar; Convenio III de Ginebra relativo al Trato debido a los Prisioneros de Guerra; Convenio IV de Ginebra relativo a la Protección debida a las Personas Civiles en Tiempo de Guerra; Protocolo I Adicio- 


\section{JURISDICCIÓN DEL TPIY}

Ratione Materiae Infracciones graves a las Convenciones de Ginebra de 1949, violaciones a las leyes y costumbres de guerra, genocidio y crímenes contra la humanidad (lesa humanidad).

Ratione Temporis La competencia temporal se extiende al periodo que comienza el 1o. de enero de 1991.

Ratione Personae El tribunal tiene competencia con respecto a las personas y Ratione Loci físicas de acuerdo con las disposiciones de su Estatuto (responsabilidad penal individual), y se extiende al territorio de la antigua República Federal Socialista de Yugoslavia, incluyendo su espacio terrestre, aéreo y aguas territoriales.

De igual forma, conforme al artículo 3o. del Estatuto del TIPY, éste tiene el poder de juzgar a personas ${ }^{5}$ que hayan cometido violaciones a las leyes y costumbres de guerra; actos tales como: utilización de armas ponzoñosas o de otro tipo que causen sufrimientos innecesarios; destrucción deliberada de ciudades, pueblos o villas; devastación no justificada por

nal a los Convenios de Ginebra del 12 de agosto de 1949 relativo a la Protección de las Víctimas de los Conflictos Armados Internacionales. Aprobado el 8 de junio de 1977 y aplicable en los conflictos armados. Entrada en vigor: 7 de diciembre de 1978 de acuerdo con el artículo 95; Protocolo II adicional a los Convenios de Ginebra del 12 de agosto de 1949 relativo a la Protección de las Víctimas de los Conflictos Armados sin Carácter Internacional. Aprobado el 8 de junio de 1977 y aplicable en los conflictos armados. Entrada en vigor: 7 de diciembre de 1978, de acuerdo con el artículo 95.

5 La responsabilidad penal individual o de las personas, conforme al Estatuto del TPIY, se aplica a quienquiera que haya planificado, incitado a cometer, ordenado, cometido, o ayudado y alentado de cualquier forma a planificar, preparar o ejecutar los crímenes que sancionan los artículos 20. a 5o. (Convenciones de Ginebra de 1949, Violaciones a las Leyes y Costumbres de Guerra, Genocidio y Crímenes contra la Humanidad), es individualmente responsable de dicho crimen. También, la categoría oficial de un acusado, ya sea como jefe de Estado o de gobierno, o como alto funcionario, no lo exonera de la responsabilidad penal y no es motivo de disminución de la pena; el hecho de que cualquiera de los actos contemplados en los artículos 20. a 5o. del estatuto, haya sido cometido por un subordinado, no libera a su superior de la responsabilidad penal si sabía o tenía razones para saber que el subordinado se prestaba a acometer ese acto o ya lo hubiera hecho, y el superior no tomó las medidas necesarias y razonables para impedir que dicho acto no fuera cometido, o para castigar a los autores. El hecho de que un acusado haya actuado en la ejecución de una orden de un gobierno o de un superior no le exonera de su responsabilidad penal, pero puede ser considerado como un motivo de disminución de la pena si el tribunal lo estima conforme a la justicia (artículo 6o.: personal jurisdiction; artículo 7o.: individual criminal responsibility: Statute of the International Tribunal as adopted 25 May 1993 by UN-SC Resolution 827, as amended 13 May 1998 by Resolution 1166, as amended 30 November 2000 by Resolution 1329). 
necesidad militar; atacar o bombardear, por cualquier medio, ciudades, aldeas, pueblos o edificios que no estén defendidos; toma, destrucción o daño deliberado hecho a edificios dedicados al culto religioso, la beneficencia y la educación, las artes y ciencias, monumentos históricos y obras de arte y ciencia, al igual que el saqueo de propiedad pública y privada. ${ }^{6}$

También, de acuerdo con el artículo 4o. del estatuto del tribunal, éste puede procesar a personas por haber cometido genocidio, definido como actos cometidos con la intención de destruir total o parcialmente a un grupo nacional, étnico, racial o religioso como tal. Tales actos comprenden asesinato de miembros del grupo; lesión grave física o mental a los miembros del grupo; sometimiento intencional del grupo a condiciones de existencia que hayan de acarrear su destrucción física total o parcial; imposición de medidas destinadas a impedir nacimientos en el seno del grupo, y traslado por la fuerza de niños del grupo a otro. Conforme a estas conductas, los siguientes actos serán punibles: genocidio, conspiración a cometer genocidio, incitación directa y pública a cometer genocidio, intento de cometer genocidio, así como la complicidad.

Finalmente, el TPIY también está facultado a juzgar a los posibles responsables de cometer crímenes contra la humanidad en un conflicto armado, independientemente de su carácter nacional o internacional, y que los crímenes hayan sido dirigidos contra población civil. Entre los

6 El TPIY representa uno de los ejemplos más claros y precisos de la aplicación positiva del principio de jurisdicción internacional. Al respecto, conviene mencionar los 14 principios que, en opinión de Amnistía Internacional (AI), deben considerar los tribunales internacionales ad hoc y las jurisdicciones permanentes como la Corte Penal Internacional (que entró en funciones el 1o. de julio de 2002 y cuyo Estatuto de Roma contaba a esa fecha con 139 firmas y 76 ratificaciones) para el ejercicio eficaz de la jurisdicción universal: 1o. Los delitos sobre los que se debe ejercer la jurisdicción universal, son las violaciones y los abusos graves contra los derechos humanos y contra el derecho humanitario internacional; 20. El cargo oficial no exime de responsabilidad penal; 3o. Ausencia de inmunidad por delitos cometidos en el pasado; 4o. Imprescriptibilidad (para los delitos graves comprendidos en el derecho internacional); 5o. Las órdenes superiores, la coacción y la necesidad no deben ser circunstancias eximentes permisibles; 6o. Las leyes y decisiones internas adoptadas con objeto de impedir el procesamiento de una persona no pueden ser vinculantes para los tribunales de otros países; 7o. Ausencia de intromisiones políticas (la decisión de iniciar o interrumpir una investigación o un procesamiento por delitos graves corresponde únicamente al fiscal); 8o. En los casos de delitos graves comprendidos en el derecho internacional, se deben emprender investigaciones y procesamientos sin esperar a que se presenten denuncias de las víctimas o de otras personas con interés suficiente en el caso; 9o. Respeto de las garantías de juicio justo internacionalmente reconocidas; 10o. Juicios públicos y con asistencia de observadores internacionales; 11o. Se deben tener en cuenta los intereses de las víctimas, de los testigos y de sus familias; 12o. Prohibición e la pena de muerte y de otras penas crueles, inhumanas o degradantes; 13o. Cooperación internacional en las investigaciones y procesamientos; 14o. Formación eficaz de los jueces, fiscales, investigadores y abogados defensores. 
actos proscritos se encuentran: el asesinato, exterminio, esclavitud, deportación, prisión ilícita, tortura, violación, persecución fundada en motivos políticos, raciales o religiosos, y otros actos inhumanos. ${ }^{7}$ Con base en la facultad que le brinda su estatuto, este tribunal ad hoc ostenta una competencia concurrente, lo que le da la capacidad de ser simultáneamente competente con la jurisdicción nacional en el momento de juzgar a presuntos responsables de las conductas condenadas. Pero además, tiene la prioridad sobre cualquier jurisdicción nacional, y en cualquier momento del proceso éste puede solicitar oficialmente a los tribunales nacionales que se desprendan de un asunto en su favor, aplicando el principio de "cosa juzgada" (res iudicata), y prohibiendo un subsiguiente juicio si la instancia internacional ya ha resuelto.

Con base en las reformas hechas a fines de 2000, la elección de los jueces permanentes de este tribunal en específico, según dispone el párrafo primero del artículo 12 de su Estatuto ${ }^{8}$ si bien se establece que el órgano estará compuesto por dieciséis magistrados. Igualmente en el artículo 13 bis sobre la elección de los jueces permanentes, se señala que sólo catorce de éstos serán electos por la Asamblea General de la ONU de una lista remitida por el Consejo de Seguridad, por lo que los dos magistrados restantes, de acuerdo con el párrafo 4 del artículo 14: “Dos de los jueces electos o designados de acuerdo al artículo 12 del Estatuto del Tribunal Internacional para Ruanda, serán asignados por el presidente de ese tribunal, en consulta con el presidente del TIPY, para ser miembros de la Sala de Apelaciones, así como magistrados "permanentes" del tribunal".9

Por lo que respecta a los normas procesales, el TPIY dispone de Reglas de Procedimiento y Prueba "instrumento que se aplica mutatis mutandis al Tribunal de Ruanda", las cuales fueron adoptadas, a posteriori, por los jueces del Tribunal de Yugoslavia. Estas normas rigen la fase previa de la audiencia, la audiencia y los recursos, la recepción de pruebas, la protección de las víctimas y de testigos, y otros asuntos relativos al caso. Cabe mencionar que el papel de los magistrados ha sido de vital importancia, y respecto a lo estipulado por el artículo 15 del Estatuto del

7 Artículo 5o. del Estatuto del TPIY.

8 Según las reformas dispuestas por la Resolución 1329 del 30 de noviembre del 2000 por el Consejo de Seguridad de la ONU.

9 Además de las características profesionales y morales que es obvio se espera con que cuente un candidato a formar parte de este tipo de instituciones, en el caso del ICTY, se ha considerado como deber el que sea tomado en cuenta la experiencia de los jueces en derecho penal, derecho internacional, incluyendo el derecho internacional humanitario y el de los derechos humanos. 
TPIY sobre que éstos adopten el régimen que regirá los procesos, se reconoce a los magistrados un lugar preponderante en la elaboración de normas que rigen su actividad; igualmente, han tenido a menudo total libertad para adoptar la interpretación que les parezca más adecuada, eficaz y más útil. Derivado de esto, los magistrados han aprobado detalladas normas de procedimiento y prueba que, como argumenta Paul Tavernier, ${ }^{10}$ han sido acogidas como un verdadero código internacional de procedimiento penal, en las que se zanjan cuestiones esenciales; dicho procedimiento no está sometido a control alguno por parte del Consejo de Seguridad y ha sido modificado en varias ocasiones, lo que, como aclara Tavernier, puede dar la impresión de cierta improvisación. ${ }^{11}$

Por su parte, la actividad del fiscal consiste en abrir un expediente de oficio o basado en los testimonios e informes obtenidos de todo tipo de fuente, especialmente los gobiernos, los órganos de las Naciones Unidas y las organizaciones internacionales, gubernamentales y no-gubernamentales. El fiscal evalúa los informes recibidos u obtenidos y se pronuncia sobre la oportunidad o no de iniciar las diligencias. Igualmente, éste está habilitado para interrogar a los sospechosos, las víctimas y los testigos, reunir pruebas, y conducir investigaciones in situ. En el ejercicio de sus actividades, el fiscal puede, de ser necesario, solicitar el concurso de las autoridades del Estado concernido. Si se llega a decidir que se ha encontrado presunciones de delitos que dan lugar a la apertura de diligencias, el fiscal incluirá un acta de acusación en la cual expone brevemente los hechos y el crimen o los crímenes con los cuales el acusado es responsable bajo la jurisdicción del tribunal de que se trate (TPIY/TPI, Ruanda). El acta de acusación es transmitida a un juez de alguna de las Salas de Primera Instancia. El fiscal es nombrado por el Consejo de Seguridad y dispone de su oficina y su personal; éstos son nombrados por el secretario general de la ONU a recomendación de la Fiscalía.

Por lo que respecta al procedimiento propiamente dicho, previo a que se dé la "apertura y conducción del proceso", existe el denominado exa-

10 Tavernier, Paul, "La experiencia de los Tribunales Penales Internacionales para la ex-Yugoslavia y Ruanda", Revista Internacional de la Cruz Roja, Ginebra, CICR, núm. 144, 1 de noviembre de 1997, pp. 645-653.

11 Las "Normas de procedimiento y prueba", adoptadas el 11 de febrero de 1994, han sido modificadas en 22 ocasiones. Con base en la última reforma hecha a las Reglas de Procedimiento y Prueba del TPIY, la redacción y distribución quedó conforme a diez partes y 127 artículos (para consultar las Reglas de Procedimiento y Prueba del TPIY, se sugiere visitar el siguiente sitio en Internet: 
men de la acusación en el que también pueden participar los jueces ad litem. Este razonamiento, que es realizado por uno de los jueces de una de las Salas de Primera Instancia, que actúa como receptor del acta de acusación para su análisis, si estima que el fiscal ha establecido que a la vista de las presunciones hay motivos para iniciar las diligencias, se confirmará el acta o no. De darse la calificación, dicho juez, a solicitud del fiscal "la única parte acusadora reconocida formalmente por el tribunal", emite los autos y el mandato de arresto o de detención para que sean presentados o remitidos el o los presuntos implicados, así como todos los demás autos necesarios para continuar con la apertura y conducción del proceso de cargo y descargo de pruebas. Ante la apertura de un proceso, la Sala de Primera Instancia que lleva el caso debe ocuparse de que éste sea imparcial y expedito, y que la instancia se desarrolle de acuerdo con las Reglas de Procedimiento y Prueba que los derechos del acusado sean plenamente respetados y que la protección de las víctimas y los testigos estén garantizados. Toda persona indiciada, y que se encuentre en custodia como consecuencia de una ordenanza o un mandato de arresto emitido por el TPIY, debe ser informada inmediatamente de los cargos en su contra y ser transferida a la unidad de detención del tribunal.

Posteriormente, la Sala de Primera Instancia encargada del caso, dará lectura del acta de acusación, se asegurará que los derechos del acusado sean respetados, confirmará que el acusado ha comprendido el contenido del acta y le instruirá a que manifieste sus alegatos. La sala fija entonces la fecha del proceso. Una vez en la audiencia, éstas serán públicas, a menos que en la sala se decida realizarlas a puerta cerrada de acuerdo con sus reglas de procedimiento y prueba. En el estatuto del tribunal, se preceptúan cuatro derechos básicos del acusado:

1. Todas las personas serán iguales ante el tribunal.

2. Toda persona contra la cual se efectúen acusaciones, tiene derecho a que su causa sea atendida imparcial y públicamente, con la reserva de la protección que dispondrán las reglas de procedimiento y prueba, que señalan deben darse medidas de salvaguarda a las víctimas y testigos que comprenden, como mínimo, las audiencias a puerta cerrada y la protección de la identidad de las víctimas.

3. Toda persona indiciada es presumida inocente hasta que se establezca su culpabilidad de acuerdo con las disposiciones del estatuto. 
4. Toda persona contra la cual pese una acusación en virtud del estatuto, tiene derecho, en uso del principio de igualdad de, al menos, las siguientes garantías:

a) Ser informada, en el más breve plazo posible, en una lengua que comprenda y de forma detallada, de la naturaleza y los motivos de la acusación en su contra.

b) Disponer del tiempo y las facilidades necesarios para la preparación de su defensa, y de comunicarse con el abogado de su elección.

c) Ser juzgado sin indebida demora.

d) Estar presente en su proceso y defenderse en su propia persona o tener la asistencia de un abogado de su elección, ser informado de su derecho a tener consejo legal y, cada vez que el interés de la justicia lo exija, tener un defensor de oficio, sin cargo alguno si no tiene medios para pagarlo.

e) Interrogar o hacer interrogar a los testigos de cargo, obtener en las mismas condiciones, la comparecencia y el interrogatorio de éstos.

f) Hacerse asistir gratuitamente por un interprete si no comprende la lengua en que se lleve la audiencia.

g) No ser forzado a dar testimonio en su contra o declararse culpable.

La sala se pronunciará con una sentencia, impondrá penas ${ }^{12}$ y sanciones contra los culpables de graves violaciones ante el derecho internacional humanitario. La sentencia será leída en audiencia pública por la mayoría de los jueces de la sala, será motivada, entregando los diversos razonamientos por escrito, y existe la posibilidad de adjuntar opiniones individuales o disidentes. ${ }^{13}$

Ante la imposición de una pena, cabe el recurso de apelación, conociendo de ésta la Sala de Apelaciones, a petición sólo de la(s) persona(s) condenada(s) por alguna Sala de Primera Instancia, no obstante también puede originarse a petición del fiscal, pero sólo bajo los siguientes su-

12 Según lo establece el artículo 24 del Estatuto del TPIY, las penas sólo comprenden el encarcelamiento, impuesto por alguna de las salas de primera instancia, recurriendo a la práctica general con respecto a las penas de prisión. Para lo cual, se deben tener en cuenta factores como la gravedad de la infracción y las circunstancias individuales del sentenciado; pero además, se puede imponer la restitución a sus propietarios legítimos de todos los bienes y recursos que les hayan sido arrebatados por medios ilícitos, incluyendo la coerción. Cabe señalar que la ejecución de la pena de reclusión puede ser llevada en cualquier otro Estado designado sobre una lista de naciones que hayan hecho saber al Consejo de Seguridad de la ONU, que están dispuestos a recibir a los condenados: la condiciones de prisión estarán sometidas a las reglas nacionales del Estado designado, bajo el control del tribunal.

13 Artículo 23 del Estatuto del TPIY. 
puestos: a) que se presuma error en una cuestión de derecho invalidando la decisión, y $b$ ) un error de hecho que haya ocasionado un "error judicial" o negación de justicia, miscarriage. En dado caso, la Sala de Apelaciones puede confirmar, anular o modificar las decisiones de la Sala de Primera Instancia. ${ }^{14} \mathrm{Si}$ se descubre un nuevo hecho desconocido en el momento del proceso en primera instancia o en apelación, y que podría haber sido un elemento decisivo en la decisión, el procesado o el fiscal pueden presentar al tribunal una demanda de revisión de la sentencia. ${ }^{15}$

Conforme al derecho del tribunal, existe la oportunidad de que el sentenciado pueda beneficiarse de un indulto o una conmutación de la pena en virtud de las leyes del Estado en la cual esté recluido. Dicha decisión deberá ser comunicada al tribunal, que resolverá en comunión de los magistrados y el presidente del tribunal, según los intereses de la justicia y sobre la base de los principios generales de derecho. Por el carácter internacional del tribunal, el origen de donde dimana su poder y jurisdicción: el Consejo de Seguridad de la ONU que lo ha establecido y la Asamblea General que participa en la nominación y elección de los jueces, todos los miembros de la organización deben colaborar con el TPIY en la búsqueda y en los juicios de aquellas personas acusadas de haber cometido graves violaciones al derecho internacional humanitario.

\section{El PROCESO SEGUIDO A SLOBODAN MilOSEVIC ANTE EL TRIBUNAL PENAL INTERNACIONAL PARA LA ANTIGUA YUGOSLAVIA}

Desde el ascenso al poder de Vojislav Kostunica, y de la formulación de acusaciones por abuso de poder y malversación de fondos en su contra, Slobodan Milosevic, permaneció oculto de la justicia serbia, hasta que el 1o. de abril de 2001 fue detenido y encarcelado en la prisión central de Belgrado. A partir del momento de su detención, y aun tiempo atrás, el gobierno serbio fue presionado intensamente por las naciones occidentales, con el objetivo de realizar arreglos y reformas pertinentes para que Milosevic fuera "extraditado" al TPIY, y enfrentara cargos por crímenes contra la humanidad. La presión internacional, principalmente de parte de occidente, fue tan efectiva que desde antes de la detención de Milo- 
sevic, se comenzó una acelerada adhesión del país a la Convención para la Prevención y Sanción del Delito de Genocidio, a la Convención contra la Tortura y otros Tratos o Penas Crueles, Inhumanos o Degradantes, y que culminó con la propia aceptación de parte del Consejo de Seguridad de la solicitud de la RFY como miembro de la ONU; todo ello para que el inculpado pudiera ser entregado para ser procesado por el TPIY. Así, el 29 de junio de 2001, Milosevic fue trasladado a La Haya para ser juzgado por crímenes contra la humanidad.

De ahí hasta nuestros días, el caso ha ido tomando sesgos interesantes que conviene destacar en su generalidad, pues la información fidedigna y detallada sobre el proceso no está circulando con facilidad dada la confidencialidad y discreción con que se está manejando el asunto, así como por algunos problemas de forma y fondo judicial que ha estado enfrentando la fiscal del tribunal, la reconocida abogada Carla del Ponte.

Slobodan Milosevic, acusado por la Fiscalía del TPIY, en tanto que ex-presidente de la República Federal de Yugoslavia, ex-comandante supremo del Ejército Popular de Yugoslavia y ex-presidente del Supremo Consejo de Defensa, así como detentador de los poderes obtenidos de facto, enfrenta tres acusaciones:

1. Acusación Kosovo (acusación originalmente confirmada el 24 de mayo de $1999,{ }^{16}$ reformada por primera vez el 29 de junio de 2001 , y tras una segunda reforma hecha el 16 de octubre, fue confirmada el 29 de octubre de 2001). ${ }^{17}$

2. Acusación Croacia (remitida por la Fiscalía el 27 de septiembre y confirmada el 8 de octubre de 2001). ${ }^{18}$

3. Acusación Bosnia y Herzegovina (confirmada el 22 de noviembre de 2001). ${ }^{19}$

En la Acusación Kosovo, ha sido inculpado inicialmente, en una primera acusación librada a finales de mayo de 1999, que después se reformó en dos ocasiones y fue confirmada el 29 de octubre del 2001, como

16 La Acusación Kosovo, por la entonces Fiscalía a cargo de Louise Arbour, se realizó el 22 de mayo de 1999 y fue confirmada dos días después.

17 Esta segunda reforma hecha a la acusación original, ya fue presentada por la fiscal Carla del Ponte, quien había sido designada en su cargo por el Consejo de Seguridad de las Naciones Unidas el 11 de agosto de 1999. El fiscal del TPIY, que es el mismo para el Tribunal de Ruanda, es electo para un periodo de cuatro años con posibilidad de reelección.

18 Documento; Indictment. The International Criminal Tribunal for the Former Yugoslavia/The Prosecutor of the Tribunal against Slobodan Milosevic: "The Indictment Croatia" (índice: CASE NO. IT-01-50-I).

19 Acusación única que hace referencia al crimen de genocidio. 
individualmente responsable por conductas criminales sucedidas en Kosovo, entre el 1o. de enero y el 20 de junio de 1999, tales como deportación, asesinato y persecución considerados crímenes contra la humanidad y sancionados en el artículo 5o. del Estatuto del TPIY, además del crimen de asesinato en su calidad de violación a las leyes y costumbres de guerra, penados por el artículo 3o. del Estatuto y el artículo 3.1.(a) de las Convenciones de Ginebra. En esta acusación, Milosevic es acusado en forma conjunta con Milan Milutinovic (ex-presidente de Serbia, exmiembro del Supremo Consejo de Defensa), Dragoljub Ojdanic (ex-dirigente del Ejército de Yugoslavia), Nikloa Sainovic (Vice-primer ministro de la RFY), y Vlajko Stojilkovic (ministro del interior de Serbia). ${ }^{20}$

La acusación señala, aún hecha contra un grupo de líderes serbios, que las pretensiones de la Fiscalía buscan deslindar responsabilidades de forma individual, en el entendido que cada sujeto planeó, instigó, ordenó, cometió, o de otra forma ayudó o fue cómplice en la organización, preparación y ejecución de los crímenes. Sin embargo, la acusación aclara que al mencionar la palabra "cometieron", se hace referencia a la participación en una acción conjunta como co-perpetradores y no se intenta sugerir que los acusados cometieron tales crímenes físicamente y en persona. Así, esta acusación señala que en la fecha señalada, fuerzas de la RFY actuaron bajo la dirección, el estímulo o el apoyo de Slobodan Milosevic, realizando una campaña de terror y violencia dirigida contra civiles de origen albanés en Kosovo. El propósito de esta misión criminal fue la expulsión de una porción importante de albano-kosovares del territorio de esta provincia en un esfuerzo por asegurar el control serbio. Para lograr sus objetivos criminales, se señala, cada uno de los acusados actuó individualmente o en forma concertada entre estos y otros conocidos y no conocidos, usando los poderes de jure y de facto favorables a ellos. También, se pretende sean encontrados culpables los ya mencionados en la

20 Sobre el paradero de estos cuatro acusados, es necesario mencionar que sobre dos de ellos: Milan Milutinovic y Vlajko Stojilkovic han sido dictadas órdenes de aprehensión a diversos Estados en particular, sin embargo, aún se encuentran libres. Por lo que respecta a Nikola Sainovic y Dragoljub Ojdanic, quienes han sido acusados de forma conjunta a Milosevic en el Caso Kosovo, una vez que fueron transferidos a la Unidad de Detención del TPIY (2 de mayo y 25 de abril del 2002, respectivamente), Ojadnic se declaró no culpable de todos los cargos en su contra en su primera comparecencia ante el tribunal el 26 de abril del 2002, misma declaración que presentó Sainovic el 3 de mayo del 2002, en su también primer comparecencia. Hemos de aclarar al lector que por limitaciones de tiempo y espacio, la presente contribución se centrará exclusivamente en desarrollar lo que directamente atañe al caso de Slobodan Milosevic; de momento, abordar la situación de los demás inculpados, rebasa nuestras pretensiones iniciales. 
Acusación Kosovo, no sólo por las acciones cometidas a título personal, sino en función de las acciones y omisiones de sus subordinados, de acuerdo al artículo 7(3) del estatuto del tribunal.

Se describe que fuerzas serbias y de la RFY, en forma deliberada, generalizada y sistemática, expulsaron y desplazaron internamente de sus hogares a aproximadamente 800 mil kosovares de origen albano por toda la provincia. Para facilitar las expulsiones y los desplazamientos, las mencionadas fuerzas militares crearon intencionalmente una atmósfera de miedo y opresión a través del uso de la fuerza, la amenaza y la violencia, recurriendo a una campaña sistemática de destrucción de propiedades de kosovo-albaneses, el ataque de pueblos y villas, el incendio inducido y la destrucción de casas, granjas, negocios, monumentos culturales y sitios de culto, lo cual provocó que regiones completas fueran inhabitables para estas víctimas.

Las prácticas: insultos raciales, calumnias, actos degradantes y otras formas de maltrato físico y psicológico, tuvieron su base en motivos raciales y religiosos, así como preferencias políticas; todos los sectores de la sociedad albano-kosovar en la provincia fueron desplazados: mujeres, niños, adultos mayores y enfermos. Enormes grupos fueron desplazados a la frontera con la República de Albania y la República de Macedonia. Por el terror que se causó a la población, muchos de estos se vieron obligados a huir a zonas montañosas, muchos fallecieron a causa de las severas condiciones climáticas, falta de alimento, inadecuada atención médica o por agotamiento.

Conforme a todos estos antecedentes, la Fiscalía del TPIY, pretende que Slobodan Milosevic sea juzgado, así como los demás mencionados, por los siguientes cinco cargos:

- Un cargo de violación a las leyes y costumbres de guerra conforme al artículo 3o. del estatuto: matar intencionalmente (murder)

- Cuatro cargos de crímenes contra la humanidad conforme al artículo 5o. del estatuto: deportación o traslado forzoso de población, asesinato, y persecución fundada en motivos raciales, políticos y religiosos.

Para concluir esta acusación, además de plantear el contexto personal de los acusados al momento de cometer los crímenes, la Fiscalía incluye una serie de listas que materializan las imputaciones: 


\begin{tabular}{|c|c|c|c|}
\hline LISTA & $\begin{array}{l}\text { CARACTERÍSTICAS } \\
\text { PROPORCIONADAS }\end{array}$ & $\begin{array}{c}\text { FECHA DE LOS } \\
\text { ACONTECIMIENTOS }\end{array}$ & $\begin{array}{l}\text { RELACIÓN } \\
\text { (NÚMERO } \\
\text { DE PERSONAS } \\
\text { ENLISTADAS) }\end{array}$ \\
\hline A & $\begin{array}{l}\text { Nombre/edad } \\
\text { aproximada/sexo }\end{array}$ & $\begin{array}{l}\text { Personas conocidas por nombre } \\
\text { asesinadas en la ciudad de } \\
\text { Racak el } 15 \text { de enero de } 1999\end{array}$ & 45 \\
\hline B & $\begin{array}{l}\text { Nombre/edad } \\
\text { aproximada/sexo }\end{array}$ & $\begin{array}{l}\text { Personas conocidas por nombre } \\
\text { asesinadas en la ciudad de Bela } \\
\text { Crkva/Bellacërkvë el } 25 \text { de } \\
\text { marzo de } 1999\end{array}$ & 55 \\
\hline $\mathrm{C}$ & $\begin{array}{l}\text { Nombre/edad } \\
\text { aproximada/sexo }\end{array}$ & $\begin{array}{l}\text { Personas conocidas por nombre } \\
\text { asesinadas en las ciudades de } \\
\text { Mali Krusa/Krushë e Vogel y } \\
\text { Velika Krusa/Krushë e Mahde el } \\
26 \text { de marzo de } 1999\end{array}$ & 101 \\
\hline D & $\begin{array}{l}\text { Nombre/edad } \\
\text { aproximada/sexo }\end{array}$ & $\begin{array}{l}\text { Personas asesinadas en la ciudad } \\
\text { de Dakovica/Gjakove el } 26 \text { de } \\
\text { marzo de } 1999\end{array}$ & 6 \\
\hline $\mathrm{E}$ & $\begin{array}{l}\text { Nombre/edad } \\
\text { aproximada/sexo }\end{array}$ & $\begin{array}{l}\text { Personas conocidas por nombre } \\
\text { asesinadas en la ciudad de } \\
\text { Paladishte/Paladishtë el } 26 \text { de } \\
\text { marzo de } 1999\end{array}$ & 19 \\
\hline $\mathrm{F}$ & $\begin{array}{l}\text { Nombre/edad } \\
\text { aproximada (dato no } \\
\text { proporcionado por la } \\
\text { mayoría)/sexo }\end{array}$ & $\begin{array}{l}\text { Personas conocidas por nombre } \\
\text { asesinadas en la ciudad de } \\
\text { Izbica/Izbicë el } 28 \text { de marzo de } \\
\text { 1999/Personas muertas por } \\
\text { fuego inducido masculino no } \\
\text { identificado }\end{array}$ & $117 / 2 / 1 / 1$ \\
\hline G & $\begin{array}{l}\text { Nombre/edad } \\
\text { aproximada/sexo }\end{array}$ & $\begin{array}{l}\text { Personas conocidas por nombre } \\
\text { asesinadas en la ciudad de } \\
\text { Dakovica/Gjakovë el } 28 \text { de } \\
\text { marzo de } 1999\end{array}$ & 20 \\
\hline $\mathrm{H}$ & $\begin{array}{l}\text { Nombre/edad } \\
\text { aproximada/sexo }\end{array}$ & $\begin{array}{l}\text { Personas conocidas por nombre } \\
\text { asesinadas en la ciudad de } \\
\text { Vucitr/Vushtrii el } 2 \text { de mayo de } \\
1999\end{array}$ & 104 \\
\hline
\end{tabular}




\begin{tabular}{|c|c|c|c|}
\hline LISTA & $\begin{array}{l}\text { CARACTERÍSTICAS } \\
\text { PROPORCIONADAS }\end{array}$ & $\begin{array}{c}\text { FECHA DE LOS } \\
\text { ACONTECIMIENTOS }\end{array}$ & $\begin{array}{l}\text { RELACIÓN } \\
\text { (NÚMERO } \\
\text { DE PERSONAS } \\
\text { ENLISTADAS) } \\
\end{array}$ \\
\hline I & $\begin{array}{l}\text { Nombre/edad } \\
\text { aproximada/sexo }\end{array}$ & $\begin{array}{l}\text { Personas conocidas por nombre } \\
\text { asesinadas en la ciudad de } \\
\text { Meja/Mejë el } 27 \text { de abril de } 1999\end{array}$ & 18 \\
\hline $\mathrm{J}$ & $\begin{array}{l}\text { Nombre/ sexo (todos } \\
\text { del sexo masculino) }\end{array}$ & $\begin{array}{l}\text { Personas conocidas por nombre } \\
\text { asesinadas en la prisión de } \\
\text { Dubrava/Dubravë ente el } 22 \text { y } \\
23 \text { de mayo de } 1999\end{array}$ & 26 \\
\hline K & $\begin{array}{l}\text { Nombre/edad } \\
\text { aproximada/sexo }\end{array}$ & $\begin{array}{l}\text { Personas conocidas por nombre } \\
\text { asesinadas en la ciudad de Suva } \\
\text { Reka/Suharekë el } 26 \text { de marzo } \\
\text { de } 1999\end{array}$ & 44 \\
\hline $\mathrm{L}$ & $\begin{array}{l}\text { Nombre/edad } \\
\text { aproximada/sexo }\end{array}$ & $\begin{array}{l}\text { Personas conocidas por nombre } \\
\text { asesinadas en las ciudades de } \\
\text { Kotilna/Kotlinë el } 24 \text { de marzo } \\
\text { de } 1999 \text {, la ciudad de } \\
\text { Saltina/Sllatinë el } 13 \text { de abril de } \\
\text { 1999, la ciudad de } \\
\text { Stagovo/Stagovë el } 21 \text { de mayo } \\
\text { de } 1999, \text { y la ciudad de } \\
\text { Dubrava/Lisnaje el } 25 \text { de mayo } \\
\text { de } 1999\end{array}$ & $17 / 13 / 12 / 8$ \\
\hline
\end{tabular}

En segundo término, la Acusación Croacia, que fue remitida al tribunal para la etapa de examen de la acusación por la fiscal Carla del Ponte, el 27 de septiembre del 2001, fue confirmada el 8 de octubre del mismo año, acusando a Slobodan Milosevic de presuntamente haber cometido crímenes contra la humanidad, graves violaciones a las Convenciones de Ginebra de 1949, y violaciones a las leyes y costumbres de guerra en la República de Croacia entre el 1o. de agosto de 1991 y el junio de 1992. Apelando al artículo 7(1) del Estatuto del TPIY, Slobodan Mlosevic es acusado como individualmente responsable de actos criminales referidos en los artículos 2o., 3o. y 5o.: graves violaciones a las Convenciones de Ginebra, violaciones a las leyes y costumbres de guerra y crímenes contra la humanidad, donde el acusado planeó, instigó, ordenó, cometió, o de 
otra forma ayudó o fue cómplice en la organización, preparación y ejecución de los crímenes, siendo el propósito de la acusación establecer la responsabilidad por la participación en una acción criminal conjunta como co-perpetrador.

El objetivo de esta acción criminal conjunta fue desplazar por la fuerza a la mayoría de la población croata y de origen no-serbio de aproximadamente una tercera parte del territorio de la República de Croacia, donde el acusado planeó que dicha zona pasara a ser parte de un nuevo Estado de dominio serbio que incluso fueron consideradas por las autoridades serbias como Distritos Autónomos Serbios (DAS), en las ciudades de Krajina, Slavonia, Slavonia Occidental, Baranja y Srem Occidental, reconocidas por las fuerzas serbias a partir del 19 de diciembre de 1991 como la República Serbia de Krajina y la República de Dubrovnik.

Esta campaña, o acción criminal conjunta, tuvo lugar a partir del 10. de agosto de 1991 y continuó hasta finales de junio de 1992. Pese a que la acusación se dirige especialmente a Milosevic, se señala que tales crímenes fueron cometidos con la participación o a través de otros individuos, cada uno participando dentro de sus funciones como co-perpetrador, incluyendo a, pero no limitado a estos: Borisav Jovic, Branco Kostic, Veljko Kadijevic, Balgoje Adzic, Milan Babic, Milan Martic, Goran Hadzic, Jovica Stanisic, Franko Simatovic (también conocido como "Frenki"), Tomislav Simovic, Vojislav Seselj, Mormir Bulatovic, Aleksandar Vasiljevic, Radovan Stojicic (también conocido como "Badza"), Zeljko Raznatovic (también conocido como "Arkan"), así como otros conocidos y no conocidos que también participaron. ${ }^{21}$ Sobre el directamente inculpado, se acusa que Slobodan Milosevic participó en una acción criminal conjunta, actuando a título personal o con la colaboración de los demás señalados, en la siguiente forma:

- Proveyeron dirección y asistencia a los líderes políticos de los, establecidos por la fuerza, distritos autónomos serbios de Slavonia, Sla-

21 En los párrafos 10 a 23 de la Acusación Croacia, se describen las funciones de los inculpados en el contexto de las actividades realizadas por éstos al momento de cometerse los crímenes. Entre las funciones que realizaban, algunos se desempeñaron como presidente de la República Federal Socialista de Yugoslavia, de la República de Montenegro, vicepresidentes de las mismas, líderes del Ejército Popular de Yugoslavia, líderes de las Unidades de Defensa Territorial, de la Defensa Nacional, de los servicios de inteligencia, jefes de operaciones especiales de la policía, altos funcionarios, presidentes del Consejo Nacional Serbio; todos con la característica de tener el poder de dirigir las acciones criminales que se señalan en la acusación. 
vonia Occidental, Baranja y Srem Occidental, Krajina, logrando el dominio de estas áreas y el subsiguiente traslado forzoso de la población croata y de origen no-serbio.

- Suministraron apoyo financiero, material y logístico a las fuerzas militares regulares e irregulares para el dominio de estas áreas con el fin de lograr los desplazamientos.

- Manipularon los órganos del gobierno de la República de Serbia con el fin de crear fuerzas armadas distintas de las de la Federación para actuar fuera en las regiones mencionadas de Croacia.

- Participaron en la formación, financiamiento, suministro, apoyo y dirección de fuerzas especiales del Ministerio del Interior de la República de Serbia. Estas fuerzas especiales fueron creadas para apoyar la ejecución de los crímenes que se señalan.

- Participaron en la ayuda financiera, logística y política de fuerzas irregulares y paramilitares serbias.

- Ejercieron control efectivo y una importante influencia sobre el Ejército Popular de Yugoslavia, el cual participó en la planeación, preparación y ejecución de los desplazamientos a la población y regiones señaladas.

- Suministraron apoyo financiero, logístico y político a las Unidades de Defensa Territorial, así como a grupos de voluntarios en las regiones mencionadas, y quienes incurrieron también en crímenes penados por el Estatuto del tribunal: artículos 2o., 3o. y 5o.

- Indudablemente ordenaron el abuso de leyes y regulaciones con el objetivo de envolver al Ejército Popular de Yugoslavia, a las Unidades de Defensa Territorial y a las unidades de voluntarios serbios en las actividades realizadas en Croacia.

- Dirigieron, comandaron, controlaron y de otra forma proveyeron importante asistencia y apoyo a los cuerpos y fuerzas militares señaladas para cometer los crímenes.

- Financiaron fuerzas militares serbias, policía y soldados paramilitares o irregulares en Croacia, quienes también cometieron los crímenes señalados.

- Controlaron, contribuyeron a, y de otra forma utilizaron los medios de comunicación en Serbia para manipular la opinión pública a través de difundir "mensajes exagerados y falsos" basados en ataques étnico-racistas de croatas contra la población serbia, con el fin de crear una atmósfera de miedo y odio entre los serbios que vivían en 
Serbia y Croacia: la propaganda generada por los medios de Serbia fue una importante herramienta que contribuyó a la comisión de los crímenes en Croacia.

Así, Slobodan Milosevic es individualmente responsable de tales conductas criminales, a la vez que los otros acusados de participar en las acciones conjuntas criminales son corresponsables por el intento, conocimiento y conciencia derivados de su responsabilidad penal a título individual, originada por su participación en las acciones.

La Acusación Croacia pretende se impongan 32 cargos a Slobodan Milosevic sobre la base de su responsabilidad penal individual, artículo $7(1)$ del estatuto, así como por su responsabilidad penal como jefe superior, artículo 7(3), con:

- Nueve cargos de graves violaciones a las Convenciones de Ginebra de 1949 por el artículo 2o. del estatuto: matar intencionalmente, arresto ilícito, tortura, infligir deliberadamente grandes sufrimientos, deportación y traslado ilegales, destruir bienes y apropiarse de ellos de manera no justificada por necesidad militar ilícita y arbitrariamente.

- Trece cargos de violaciones a las leyes y costumbres de guerra en virtud del artículo 3o. del estatuto: asesinato, tortura, tratos crueles, destrucción y devastación deliberada de aldeas no justificada por necesidad militar (no sean objetivos militares), destrucción y daño deliberado hecho a instituciones dedicadas a la educación o al culto, saqueo de propiedad pública y privada, ataques a civiles, destrucción deliberada hecha a monumentos históricos y edificios dedicados a la educación o al culto, ataques deliberados a objetos civiles.

- Diez cargos de crímenes contra la humanidad en virtud del artículo 5o. del estatuto: persecución basada en motivos políticos, raciales o religiosos, exterminio, asesinato, encarcelación ilícita, tortura, actos inhumanos, deportación y actos inhumanos como el traslado forzoso de la población.

Al igual que se hace en la Acusación Kosovo, en la de Croacia se anexa una serie de listas con fecha, localidad, el nombre de las víctimas, e incluso el año de nacimiento y el sexo, de víctimas en las ciudades de Vocin, Bacin, Lipovanic, Vukovic, Saborsko, Skabrnja, Nadin, Bruska, Ovcara, Baranja, Campo de Minas Lova, Erdut, Vukovar, así como en los alrededores de Dubrovnik, que complementan, personifican o materiali- 
zan las imputaciones hechas, que dado el alcance de la masacre, corresponden al cargo de matar intencionalmente o asesinato.

Por último, la Acusación Bosnia y Herzegovina, confirmada el 22 de noviembre del 2001, pretende que Slobodan Milosevic sea juzgado por eventos que sucedieron en la República de Bosnia y Herzegovina entre 1992 y 1995. Se acusa a Milosevic como individual y penalmente responsable de graves violaciones a las Convenciones de Ginebra de 1949, violaciones a las leyes y costumbres de guerra, genocidio y crímenes contra la humanidad, en función de lo dispuesto en los artículos 2o., 3o., 4o. y 5o. del Estatuto del TPIY. Igualmente, se le imputa al acusado de haber planeado, instigado, ordenado, cometido, o en cuya planeación, preparación y ejecución, Milosevic de alguna forma ayudó o fue cómplice; no obstante, al emplear el término "cometió" o "cometieron", la fiscal no sugiere que el acusado físicamente cometió alguno de los crímenes que pesan sobre su persona, tal expresión sugiere la "participación en una acción criminal conjunta en calidad de co-perpetrador". ${ }^{22}$ El objetivo de tal acción criminal conjunta fue el desplazamiento o traslado forzoso permanente de la mayoría de civiles no-serbios, principalmente bosnios-musulmanes y bosnios-croatas de extensas áreas de la República de Bosnia y Herzegovina. La comisión de las conductas criminales tuvo lugar el 10. de agosto de 1991, y continuó en los hechos hasta al menos el 31 de diciembre de 1995.

Una vez que la acusación atañe directamente a Slobodan Milosevic, en ella se menciona como co-perpetradores de tal acción criminal conjunta a: Radovan Karadzic, Momcilo Krajisnik, Biljana Plavsic, general Ratko Mladic,23 Borisav Jovic, Branko Kostic, Veljko Kadijevic, Blagoje Adzic, Milan Martic, Jovica Stanisic, Franko Simatovic (también conocido como "Frenki", Radovan Stojicic (también conocido como "Badza"), Vojislav Seselj, Zeljko Raznatovic (también conocido como “Arkan”), y otros participantes conocidos y no conocidos. ${ }^{24}$

22 Documento; Indictment: Milosevic “Bosnia and Herzegovina” Initial Indictment. The International Criminal Tribunal for the Former Yugoslavia / The Prosecutor of the Tribunal against Slobodan Milosevic. Índice: Case No. IT-01-51-I.

23 El general Ratko Mladic se desempeñó como comandante del Ejército Serbio en Bosnia, pese a que es requerido por el ICTY, aún se encuentra libre.

24 Con el propósito de que la acción criminal conjunta tuviera éxito, Slobodan Milosevic trabajó en forma concertada o a través de otros individuos en tal operación. Cada participante o co-perpetrador en la acción criminal, compartiendo el propósito de la misma, actuó su propio rol, lo que se significó en el éxito de la empresa. 
Dada la figura política predominante de Milosevic en Serbia, desde 1987 y hasta finales de 2000 en las entidades políticas de la República Federal Socialista de Yugoslavia y la República Federal de Yugoslavia, éste adquirió el control en todas las facetas del gobierno serbio, incluyendo la policía y los servicios de seguridad del Estado, además de que ganó control sobre los líderes políticos de Kosovo, Vojvodina y Montenegro, por lo que se aduce el ejercicio de control efectivo y verdadera influencia sobre los demás mencionados en la realización de tal acción criminal conjunta, aunado a que, actuando a título personal o con la complicidad de estos y otros conocidos y no conocidos, efectivamente controlaron e importantemente influenciaron las acciones de la Presidencia federal de la entonces República Federal Socialista de Yugoslavia y más tarde República Federal de Yugoslavia, el Ministerio Serbio de Asuntos Internos, el Ejército Popular de Yugoslavia, el Ejército Serbio-Bosnio, así como grupos paramilitares serbios. ${ }^{25}$

Así, Slobodan Milosevic, personalmente o de forma convenida con otros, realizó una acción criminal concertada en la siguiente forma:

- Ejerció control efectivo sobre elementos del Ejército Popular de Yugoslavia y posterior Ejército Yugoslavo quienes participaron en la planificación, preparación, dieron facilidades y ejecutaron el desplazamiento o traslado forzoso de la mayoría no-serbia, principalmente bosnio-musulmanes y bosnio-croatas de vastas áreas de la República de Bosnia Herzegovina.

- Proveyó apoyo financiero, logístico y político al Ejército Serbio de Bosnia, quienes también participaron en la acción criminal conjunta y son responsables de la comisión de los crímenes que sancionan los artículos 2o., 3o., 4o. y 5o. del Estatuto del TPIY.

- Ejerció una importante influencia y asistió a los líderes políticos de la auto nombrada República Serbia de Bosnia en la planeación, preparación, disposición de facilidades así como la ejecución del dominio logrado en municipalidades de Bosnia y Herzegovina, y el posterior desplazo por la fuerza de la población.

- Participó en la formación, financiamiento, suministro, apoyo y dirección de fuerzas especiales del Ministerio de Asuntos Internos de 
la República de Serbia, las cuales participaron en forma conjunta en las acciones criminales.

- Participó proveyendo soporte financiero, logístico, político y de dirección a fuerzas irregulares y paramilitares serbias, las cuales participaron en forma conjunta en las acciones criminales.

- Controló, manipuló, y de otra forma utilizó los medios de comunicación en Serbia para manipular la opinión pública a través de difundir "mensajes exagerados y falsos" basados en ataques étnicoracistas de bosnios-musulmanes y croatas contra la población serbia con el fin de crear una atmósfera de miedo y odio entre los serbios, la cual contribuyó al traslado forzoso de la mayoría no-serbia

Con fundamento en el artículo 7(3) del Estatuto del TPIY, Milosevic es penalmente responsable en calidad de jefe o autoridad superior y en función de los actos o omisiones de sus subordinados. La acusación ahonda que al menos entre marzo de 1991 hasta el 15 de junio de 1992, el inculpado ejerció el mando eficaz sobre cuatro miembros del bloque serbio en el seno de la Presidencia de la República Federal Socialista de Yugoslavia. Tales individuos eran Borisav Jovic (representante de la República de Serbia), Branko Kostic (representante de la República de Montenegro), Jugoslav Kostic (representante de la Provincia Autónoma de Vojvodina) y Sejdo Bajramovic (representante de la Provincia Autónoma de Kosovo y Metohija). Asimismo, a partir de octubre de 1991, sirviéndose de la ausencia de los representantes de Croacia, Eslovenia, Macedonia y Bosnia Herzegovina de la Presidencia federal, los cuatro miembros del bloque serbio ejercieron de facto los poderes de la Presidencia, incluyendo la Comandancia Colectiva del Ejército Popular de Yugoslavia. Ante tal situación, esta presidencia títere actuó sin disensión alguna para ejecutar las políticas de Slobodan Milosevic.

Así, la Acusación Bosnia Herzegovina imputa a Milosevic de responsabilidad individual criminal (artículo 7(1) del estatuto, y responsabilidad penal como jefe o autoridad superior (artículo 7(3)) con los siguientes veintinueve cargos: ${ }^{26}$

- Dos cargos por el crimen de genocidio y complicidad en este crimen en virtud del artículo 4o. del Estatuto.

26 Cfr. Párrs. 32 a 45, Acusación Bosnia y Herzegovina, Tribunal Penal Internacional para la antigua Yugoslavia. 
- Diez cargos por crímenes contra la humanidad, incluyendo persecución, exterminio, asesinato, prisión ilegal, tortura, deportación y actos inhumanos como desplazamiento o traslado por la fuerza, bajo lo dispuesto en el artículo 5o. del Estatuto del TPIY.

- Ocho cargos por graves violaciones a las Convenciones de Ginebra de 1949, tales como matar intencionalmente, confinamiento ilegal, tortura, infligir deliberadamente graves sufrimientos, deportación ilegal o traslado por la fuerza, destrucción masiva y apropiación de propiedades conforme al artículo 2o. del estatuto.

- Nueve cargos por violaciones a las leyes y costumbres de guerra incluyendo ataques inter alia sobre población civil, destrucción ilícita, saqueo y tratos crueles conforme al artículo 3o. del Estatuto.

Para concluir, en la parte final de la acusación se presentan seis listas con nombres de personas ejecutadas; detenidos que posteriormente fueron asesinados; personas confinadas, desplazados, incidentes de mutilaciones, y nombres de personas localizadas en zonas donde se dirigieron bombardeos contra la población civil.

\section{DESARROLLO GENERAL DE LAS COMPARECENCIAS EN EL JUICIO A SLOBODAN MILOSEVIC}

Por lo que respecta a la comparecencia del sujeto incriminado ante el TPIY, una vez que éste fue detenido en Serbia por fuerzas locales el 1 de abril del 2001 — acusado por los tribunales de su país de malversación de fondos públicos y abuso de poder, y no precisamente para su entrega a La Haya-, quedó en situación de prisión preventiva, para finalmente, tras la presión de la comunidad internacional, ser entregado al tribunal el 29 de junio de ese mismo año.

Una vez en el tribunal, las primeras comparecencias de Milosevic fueron el 3 de julio del 2001 por la Acusación Kosovo, el 29 de octubre de 2001 por la Acusación Croacia, y el 11 de diciembre de 2001 por la Acusación Bosnia Herzegovina, en tres de las cuales se limitó a señalar que no reconocía la autoridad del TPIY y que se reservaba su derecho a callar, situación por la que fue considerada tal decisión como una declaración de "no culpable". El juicio continúa siendo llevado por la Sala III de Primera Instancia del tribunal, la cual está presidida por el reconocido jurista y magistrado Richard May del Reino Unido, y como miembros de la 
sala, el magistrado Patrick Robinson de Jamaica y el magistrado O-Gon Kwon de Corea del Sur.

El 30 de agosto, para la Acusación Kosovo, el 30 de octubre para el Caso Cracia, y el 23 de noviembre de 2001 para el Caso Bosnia Herzegovina, la sala decidió convocar al secretario del tribunal a designar consejeros para comparecer ante ella en calidad de amicus curiae, considerando que era deseable en interés de asegurar un juicio justo, para que así fueran nombrados éstos conforme a la regla 74 de las Reglas de Procedimiento y Prueba del tribunal para, no representar al acusado, pero sí para asistir a la apropiada conducción del juicio. ${ }^{27}$

Posteriormente, el 6 de septiembre, el 7 y 22 de noviembre de 2001, el secretario de la corte, señor Hans Holthuis, designó al señor Steven Kay, a Branislav Tapuskovic y al profesor Michail Wladimiroff a actuar como amici curiae en los tres casos.

Las tres acusaciones, que en un inicio serían llevadas en juicios por separado, a petición de la Fiscalía que interpuso a la Sala de Apelaciones con el fin de que fuera escuchada para solicitar se reunieran los casos Kosovo, Croacia y Bosnia en uno sólo, ésta accedió en tal sentido, pero no obstante, se decidió que la Acusación Kosovo se desahogara en un juicio por separado y se resolvió que el juicio para tal caso comenzara el 12 de febrero del 2002. Posteriormente, el 30 de enero del 2002, la Sala de Apelaciones aceptó escuchar a las partes respecto de una petición que la Fiscalía presentó sobre la decisión que no permitía unificar en un solo juicio las tres acusaciones. En esta ocasión, la Fiscalía, ${ }^{28}$ el acusado (Milosevic) y los amigos de la corte presentaron sus posiciones a la sala. Conforme a esto, la Sala de Apelaciones el 1o. de febrero del 2002, determinó que las tres acusaciones se desahogaran en un solo juicio, por lo que para este fin, los tres casos se unificaron en uno solo y ya se están juzgando como una acusación única que inició el 12 de febrero de 2002 (continuando durante todo este año) con la presentación de evidencia relevante únicamente para

27 El amigo de la corte es designado para asistir a la sala y hacer cualquier comentario público al acusado en la etapa preliminar o de examen de acusación; hacer cualquier comentario o presentar objeciones por la parte del acusado durante el proceso, así como en el interrogatorio de los testigos, tanto como sea apropiado; atraer la atención de la sala a cualquier evidencia exculpatoria o eximente; y actuar de cualquier otra forma que el amigo de la corte considere que sea apropiado para asegurar un juicio justo.

28 Cabe aclarar que, por lo que respecta a las tres acusaciones contra Milosevic, la fiscal Carla de Ponte cuenta con un equipo de tres fiscales adjuntos: la señora Peggy Kuo, y los señores Geoffrey Nice y Norman Farrell. 
el caso Kosovo, en el entendido de que esto fuera en tal forma hasta que se considerara apropiado, y entonces se introdujera evidencia también relevante para los otros casos.

Así, el 12 de febrero de 2002, el juicio del TPIY inició sus vistas con una declaración inicial de la Fiscalía seguida de una hecha por el magistrado presidente de la sala: juez Richard May. Los subsiguientes dos días, los magistrados de la sala hicieron sus primeras observaciones al Caso Kosovo, y el día 14 de febrero el acusado Slobodan Milosevic obró su primer declaración, que continuó el día siguiente, de acuerdo con las Reglas de Procedimiento y Prueba (regla 84 bis). Seguidamente, entre el 18 y el 21 de febrero, sucedieron los primeros llamamientos a declarar con testigos considerados relevantes por la Fiscalía para el Caso Kosovo: señor Mahmut Bakalli, Stephen Spargo (analista de inteligencia de la Oficina de la Fiscalía), quien detalló una serie de mapas computarizados que fueron aducidos como evidencia para el caso, pero que el acusado consideró poco relevantes pues no comprobaban las acusaciones. También fue llamado Agim Zeqiri, de la aldea de Celinë, en Kosovo, quien fue interrogado por el acusado y posteriormente por los magistrados tras permitirle que pudiera retirarse. Finalmente el 21 de febrero de 2002, la Fiscalía llamó a Fehim Elshani, un granjero de la Villa Nagafc en Kosovo, quien también fue interpelado por el acusado y brevemente por un amigo de la corte.

Continuando el juicio, siguieron siendo presentados los testigos por la Fiscalía entre el 25 y el 28 de febrero, vistas que se reanudaron el 4, 6, 7 y 8 de marzo. Así, el 11 de marzo, una vez iniciada la cuarta semana del juicio (11 al 15 de marzo), la sala dio a conocer una decisión con respecto a la admisibilidad de evidencia en virtud de la regla 92 de las Reglas de Procedimiento y Prueba del tribunal, donde se estableció en principio, que la sala admitiría solamente 23 declaraciones señaladas en una moción de la Fiscalía, limitándose a que sería un máximo de cuatro testigos por cada municipalidad en Kosovo, incluyendo las vistas que ya se habían hecho, y que todos los testigos cuyas declaraciones fueran admitidas, serían sujetos de interrogación, por lo que se autorizaba a la Fiscalía a sólo hacer a los testigos algunos cuestionamientos con carácter introductorio.

En el inter, sobre una petición presentada en forma oral por el acusado, en las audiencia del 26 y 27 de febrero del 2002, en donde Milosevic solicitaba la libertad provisional con el fin de preparar su defensa apropiadamente, ya que lo está haciendo en su propia persona, la Sala de Primera Instancia del Caso (Sala III), resolvió el 6 de marzo, teniendo en 
cuenta que dicha petición se había hecho con anterioridad a la Sala de Apelaciones el día 30 de enero de 2002, así como los comentarios de los amigos de la corte de apoyar la petición en la posibilidad de que fuera necesario para asegurar una adecuada preparación de la defensa, notando que la Fiscalía no hizo llegar algún comentario formal al respecto, apreciando que el acusado está conduciendo su defensa en persona y que el argumento dado en la petición de libertad provisional señalaba que esto le daría la oportunidad de prepararse para poder conducir adecuadamente su defensa. Asimismo, considerando la obligación del tribunal de asegurar que el acusado reciba un juicio justo, incluyendo el derecho al tiempo y las facilidades adecuadas en la preparación de su defensa, a la vez que se reconocen las dificultades prácticas, pero juzgando que su derecho a tiempo y facilidades adecuadas en la preparación de su defensa podían ser aseguradas por otros medios distintos a la libertad provisional, además de otras consideraciones (como la regla 65 de las Reglas de Procedimiento y Prueba), se negó la petición a Milosevic.

\section{COMENTARIOS FINALES}

Sin duda, el juicio a Slobodan Milosevic es el de mayor importancia y trascendencia desde los procesos desahogados por los tribunales de Nüremberg y Tokio, sin pasar por alto la particular relevancia y resultados tangibles de la actividad del Tribunal Penal Internacional para Ruanda en los casos de Jean Kambanda y Jean-Paul Akayesu. Se ha llegado a afirmar que la entrega de Milosevic al Tribunal Penal para la ex-Yugoslavia tiene detrás la imposición de Estados Unidos de América, quienes a cambio de apoyar la reconstrucción de la región, forzaron su presentación para juzgarlo por los graves crímenes que presuntamente cometió. Lo cierto es que el acusado, que tiene por defensor a su propia persona, ha sido capaz de, en un primer momento, desestimar las pruebas y alegatos de la parte acusadora, sobreponiéndose por ejemplo, uno a uno, a los testigos de la Fiscalía que no han podido realmente cuestionar su actitud, aun cuando en realidad las acusaciones han estado ampliamente sustentadas. Con todo $-\mathrm{y}$ esto parece atribuirse a ciertos errores de estrategia e indebida subestimación del inculpado por parte de la señora Del Ponte y de su equipo - no se ha logrado implicar materialmente al acusado, directa y objetivamente, en tal o cual hecho, sino únicamente en virtud de su posición de autoridad superior. 
Asimismo, observamos algún juego jurídico-político subyacente o bien una evidente falta de pericia de la fiscal al llamar a comparecer sólo a testigos - algunos de ellos inadecuadamente protegidos- que más que apoyar los hechos registrados en las acusaciones, sólo confirman las listas de personas que las complementan, debiendo más bien llamar a comparecer e interrogar con rigor a los verdaderos cómplices del inculpado, buscando que, como se hizo en Nuremberg, a través de una fuerte interrogatoria, caigan en contradicciones y pongan en evidencia a su jefe superior. En esta tónica, salta, por evidente, la sugerencia de que el tribunal evite ya continuar presentando a víctimas de suyo laceradas, amenazadas y asustadas al vivir de nuevo el horror que se les indujo, al ser careadas ante "el malvado individuo que marcó su vida para siempre", independientemente de que las conductas criminales que todos presenciamos por los medios visuales sean altamente reprobables.

Milosevic, que incluso como muestra del autodominio de sí mismo en el juicio, en una estrategia que ciertamente no se sabe si le dará resultado, ha señalado que los que debieran estar en su lugar tendrían que ser los líderes de la Alianza del Tratado del Atlántico Norte, cuya responsabilidad internacional penal a su entender es inocultable, ha llamado además la atención de la opinión pública mundial al cuestionar las acciones de las fuerzas de la OTAN, reconocidas por la ONU, las cuales, pese a lo avanzado de sus "bombas con microprocesadores integrados", también afectaron y mataron a población civil en Yugoslavia por supuestos errores de cálculo y de investigación de inteligencia, y que ciertamente cayeron sobre objetos civiles. También ha argumentado el presunto genocida que, al igual que lo hacen hoy los estadounidenses en Afganistán y en el resto del mundo, él combatió en su momento el terrorismo de los extremistas musulmanes, y recuerda que el Pentágono proporcionó ayuda al Ejército de Liberación de Kosovo y levantó el embargo de armas a Bosnia Herzegovina para avivar el fuego por supuestas consideraciones de defensa en lugar de intervenir con fuerzas de pacificación. Y además de anteponer la presunta ilegalidad de la existencia y formas del TPIY, ha señalado que él pidió al presidente Clinton expulsara a Osama bin Laden de Kosovo, y fue ignorado y que incluso el ex presidente estadounidense se alió con los musulmanes albanos en contra de los serbios. Además, un punto clave del argumento de Milosevic, es que éste mantuvo relaciones de amistad con líderes estadounidenses e ingleses posteriormente a la guerra en Bosnia y Croacia, y que incluso fue llamado "pacificador" en 
la firma de los Acuerdos de Dayton. Por todo esto, el ex-jefe serbio pretende - porque lo juzga su legítimo derecho- que sean llamados a atestiguar líderes occidentales como William Clinton, el primer ministro Tony Blair, el ex-canciller Helmut Kohl y el ex-secretario general de la OTAN, Javier Solana.

Por lo demás, ha contra-acusado a los amigos de la corte, por haberle llegado a someter mociones sin la debida documentación que las sustente, y han callado cuando Milosevic ha sido interrumpido al micrófono, apagándolo a la mitad de su declaración, cuando ha intentado referirse al tribunal, además de que ha sido denegado su derecho a comunicarse confidencialmente con su abogado no oficial.

Por otro lado, en la vorágine de opiniones que ha desatado el caso, diversos analistas consideran que la petición de la Fiscalía de unificar las acusaciones fue una estrategia con el fin de no dejar perder la primera de éstas, es decir, no pudo comprobarse con las evidencias, los testigos, lo que en el papel se argumentaba sobre la cuestión en Kosovo, de ahí que tras unirlas todas cupiera una mayor oportunidad de comprobar el nexo - difícil de fundamentar jurídicamente- entre las órdenes expresamente dadas y la ejecución de tan execrables atrocidades, de las que, irónicamente, todos en el mundo fuimos testigos al observar la "carnicería de los Balcanes", como se les llama en occidente. Y, por su parte, los testigos continúan quedando "en el aire". El pasado 12 de junio de 2002, la Fiscalía remitió un informe confidencial sobre el testigo "K5" - así denominado para "protegerlo" - y presentó una solicitud para librar una orden del tribunal. El reporte demostró que un periódico de Belgrado llamado El Nacional, publicó en su edición del 25 de mayo, un artículo en el que se revelaba la identidad del testigo protegido "K5". En consecuencia, la Sala III del caso ordenó que la publicación de esta información confidencial cesara inmediatamente, afirmando que su continuación comprometería responsabilidad internacional ante el tribunal. Asimismo, la sala ordenó al gobierno de Serbia-Montenegro una investigación a fondo de la cuestión y la adopción de medidas necesarias para el cumplimiento de su instrucción, fijando para el día 18 de julio de 2002 la entrega por el gobierno yugoslavo de un reporte oficial, lo cual fue debidamente cumplimentado hasta 45 días después del plazo ordenado.

Sin duda, este juicio llevará largo tiempo en desahogarse, pues se ha abierto con él una verdadera caja de Pandora, y por constituirse como un modelo de hechos o un "caso sombrilla" —umbrella case, así llamado en 
el common law - que se vincula y relaciona con un grupo más grande de inculpados "conocidos y no conocidos", como señalan las acusaciones: un sinnúmero de líderes políticos, militares, paramilitares y hasta grupos de voluntarios civiles.

Hoy, después de desahogadas prácticamente todas las comparecencias del caso Kosovo, y habiéndose iniciado recientemente el libramiento de pruebas y presentación de testimoniales para el caso Croacia, en el momento de escribir estas líneas, en las postrimerías del 2002, el juicio continúa su proceso conforme a lo más o menos previsto. Será importante, entonces, esperar los primeros resultados concretos para realizar una evaluación cierta, objetiva y crítica de las acciones jurídicas y de las actuaciones judiciales emprendidas por esta jurisdicción internacional ad hoc y de los alcances de la aplicación del principio de jurisdicción internacional en este importante capítulo de la justicia penal supranacional. 